\title{
AMBIENTE VIRTUAL: UM ESTUDO EXPLORATÓRIO COM ESTUDANTES UNIVERSITÁRIOS
}

\author{
Matheus Fernandes de Castro ${ }^{1}$, Lanna Gagliardi Tinoco ${ }^{2}$, Eduardo Moura Souza ${ }^{3}$, Jéssica Fernanda de Paula ${ }^{4}$ \\ ${ }^{1}$ Doutor em Psicologia Social e do Trabalho pela Universidade de São Paulo - USP. Professor Assistente Doutor e Chefe \\ do Departamento de Psicologia Experimental e do Trabalho da Universidade Estadual Paulista - UNESP, Coordenador \\ do Laboratório de Psicologia Ambiental do Departamento de Psicologia Experimental e do Trabalho (LAPA-PET). \\ ${ }^{2}$ Graduanda em Psicologia da Universidade Estadual Paulista - UNESP, Assis, SP. \\ ${ }^{3}$ Graduando em Psicologia da Universidade Estadual Paulista - UNESP, Assis, SP \\ ${ }^{4}$ Graduando em Psicologia da Universidade Estadual Paulista - UNESP, Assis, SP
}

\section{RESUMO}

Nesta pesquisa buscou-se verificar a compreensão dos estudantes de uma universidade pública do interior do estado de São Paulo, sobre o que é o Ambiente Virtual e seus impactos na vida cotidiana. Como referencial teórico, para a compreensão do conceito de ambiente e para refletir sobre o que se convencionou chamar de ambiente virtual, foi utilizada a Psicologia Ambiental. Foram realizadas e analisadas quarenta entrevistas visando destacar os sentidos atribuídos, pelos estudantes, à inter-relação entre as pessoas e o ambiente virtual. Pode-se destacar que os jovens compreendem o ambiente virtual como algo amplo e têm grande dificuldade para defini-lo claramente, apesar do vultuoso número de horas de uso. É possível destacar que os sujeitos compreendem que existe uma grande conexão de múltipla determinação entre o ambiente virtual (on-line) e o ambiente (off-line). Os resultados apontam para a grande necessidade de estudos e intervenções no que se refere aos ambientes virtuais na sociedade.

Palavras- chave: Ambiente virtual. Cotidiano. Jovens universitários.

\section{VIRTUAL ENVIRONMENT: AN EXPLORATORY STUDY WITH UNIVERSITY STUDENTS}

\section{ABSTRACT}

This research aimed to understand the students of a public university in the interior of the state of São Paulo, about what is the Virtual Environment and its impacts on everyday life. As a theoretical framework, to understand the concept of environment and to reflect on what is conventionally called virtual environment, we used Environmental Psychology. Forty interviews were conducted and analyzed to highlight the meanings attributed by students to the interrelationship between people and the virtual environment. It can be highlighted that young people understand the virtual environment as something broad and have great difficulty clearly defining it, despite the large number of hours of use. It is possible to highlight that the subjects understand that there is a great connection of multiple determination between the virtual environment (online) and the environment (offline). The results point to the great need for studies and interventions regarding the virtual environments in society.

Keywords: Virtual environment. Daily life. University students.

\section{ENTORNO VIRTUAL: UN ESTUDIO EXPLORATORIO CON ESTUDIANTES UNIVERSITARIOS}

\section{RESUMEN}

Esta investigación tuvo como objetivo comprender a los estudiantes de una universidad pública en el interior del estado de Sao Paulo, sobre qué es el entorno virtual y sus impactos en la vida cotidiana. Como marco teórico, para comprender el concepto de entorno y reflexionar sobre lo que convencionalmente se denomina entorno virtual, utilizamos la psicología ambiental. Cuarenta entrevistas se realizaron y analizaron para resaltar los significados atribuidos por los estudiantes a la interrelación entre las personas y el entorno virtual. Cabe destacar que los jóvenes entienden el entorno virtual como algo amplio y tienen 
grandes dificultades para definirlo claramente, a pesar de la gran cantidad de horas de uso. Es posible resaltar que los sujetos entienden que existe una gran conexión de determinación múltiple entre el entorno virtual (en línea) y el entorno (fuera de línea). Los resultados apuntan a la gran necesidad de estudios e intervenciones con respecto a los entornos virtuales en la sociedad.

Palabras clave: Entorno virtual. Vida cotidiana. Estudiantes universitarios.

\section{INTRODUÇÃO}

Este trabalho buscou verificar a compreensão de estudantes universitários, de uma universidade pública do interior do estado de São Paulo, sobre o que é ambiente virtual e os seus impactos na vida cotidiana. Para isso, foram estabelecidos como objetivos específicos: buscar a compreensão dos entrevistados sobre o uso dos ambientes virtuais; verificar quais os sentidos que eles atribuem a esse uso; e como compreendem possíveis impactos dos ambientes virtuais em suas relações sociais cotidianas. A Psicologia Ambiental se dedica ao estudo da inter-relação entre o sujeito e seu ambiente (CAVALCANTE; ELALI, 2018). Tal relação de trocas mútuas é extremamente dinâmica e, para ser compreendida, deve levar em consideração os aspectos físicos e sociais do ambiente.

A Psicologia Ambiental vem, por meio das pesquisadas realizadas, tentando promover a ampliação e o aprimoramento de seu campo de estudos, criticando e repensando sua definição de ambiente, para tentar vencer os desafios que as ciências enfrentam em uma sociedade tão dinâmica quanto a nossa. Segundo Moser (1998, p. 122):

Estamos preocupados em caracterizar as incidências específicas de certos micros e macros ambientes sobre 0 indivíduo. Ou seja, como, por exemplo, a casa de uma pessoa é capaz de influenciar a sua percepção, avaliação, atitudes e satisfazer suas necessidades. Mas também estamos interessados em coisas muito mais amplas, como uma cidade, por exemplo.

Fica claro que para o autor supracitado existem categorias, ou melhor, tipos de ambientes diferentes. Ele fala em micro e macro ambientes que se diferem não só pela sua dimensão geográfica, como também pela percepção e auto localização do sujeito. Moser (2018) afirma que vivemos em quatro tipos fundamentais de ambientes: o habitat (intimidade, lar), os espaços de proximidade (o bairro, a vizinhança), os espaços urbanos e naturais e o ambiente global. Uma vez que seja possível diferenciar diversos tipos de ambientes deve-se ficar atento ao fato de que eles possibilitam diversas formas de percepção, influenciando os sujeitos de diferentes maneiras.

A percepção ambiental é um fenômeno psicossocial. É como o sujeito incorpora suas experiências. Não há leitura da objetividade que não seja ou não tenha sido compartilhada; o sujeito sempre interpreta culturalmente e, a partir daí, constitui-se como identidade. Sua identidade será como se espacializa, se temporaliza, como constrói as narrativas de si próprio a partir desta espacialização e desta temporalização.

(TASSARA; RABINOVICH, 2003; p. 340).

Conforme destacado acima, o ambiente não determina o sujeito, mas o influencia de acordo com o que o sujeito é, ou seja, de acordo com sua cultura, sua história e tantos outros fatores psicossociais. Essa influência volta para a sociedade na maneira como o sujeito passa a perceber, pensar e agir.

Para a Psicologia Ambiental, ambiente é um conceito multidimensional, compreendendo o meio físico concreto em que se 
vive, natural ou construído, o qual é indissociável das condições sociais, econômicas, políticas, culturais e psicológicas daquele contexto específico. Tudo o que estiver presente em um determinado ambiente inclusive as pessoas - é parte que o constitui. Alterações sofridas em qualquer de seus componentes acarretam modificações nos demais, conferindo ao ambiente uma nova feição. Portanto, sua configuração é dinâmica e unitária, incorporando mudanças que são assimiladas pelo ambiente como um todo. (CAMPOS DE CARVALHO; CAVALCANTE; NÓBREGA, 2011, p.28).

O ambiente, então, é composto de locais naturais/construídos, por pessoas e pelas dinâmicas que estão presentes nele. Ele não é rígido e sim maleável, pois ao receber uma simples modificação em um de seus elementos, pode ser totalmente alterado, sendo, portanto, mutável e dinâmico.

Tudo isso leva a pensar a importância dos ambientes virtuais como um dos elementos que compõem o ambiente, hodiernamente. Eles têm modificado sobremaneira o espaço, a vida cotidiana, a cultura, ou seja, a sociedade como um todo. Na Geografia, Santos (2004; 2005) destaca a importância da tecnologia para a conformação do espaço atual, que ele chamou de: "meio-técnico-científico-informacional". Para o autor a internet e tudo o que ela sustenta, bem como, a infraestrutura concreta (cabos, computadores, roteadores, torres e etc.), têm interferência direta na constituição do espaço e, consequentemente, na sociedade em geral.

Desta forma, apresenta-se como uma questão importante a compreensão sobre o ambiente virtual e suas interferências na vida das pessoas. Nesse sentido, parece que encetar uma iniciativa de estudo nesse campo, é de grande importância para a Psicologia, ou para qualquer outra ciência. No entanto, não se encontra, na produção nacional da Psicologia Ambiental, uma grande atenção sobre o tema.

Rivlin (2003), ao revisar uma de suas obras, que foi seminal para a Psicologia Ambiental no mundo, já argumentava que, o aumento do uso da tecnologia no cotidiano produziu novas dimensões ambientais que devem ser exploradas e compreendidas, para o avanço da ciência. Deve-se compreender esse elemento ambiental que, sem dúvida, revolucionou a sociedade nas últimas décadas, para que se possa compreender melhor o mundo atual.

A internet surgiu na década de 70 , na América do Norte, com objetivos militares, ou seja, como forma de combater a União Soviética. Ela se expandiu, cada vez mais, até chegar ao Brasil, por volta da metade da década de 90 (DORNELLES, 2004). Assim, com seu aprimoramento e popularização, a partir dos anos 2000, foram surgindo as chamadas Redes Sociais: o primeiro serviço a ter esse status, surgiu em 2002, o chamado Friendster. Depois dele, as redes sociais se popularizaram e se tornaram um dos principais meios de comunicação e socialização (DAQUINO, 2012).

Com o passar dos anos, a tecnologia foi cada vez mais tomando conta das relações sociais e modificando-as profundamente. Para Lévy (1996; 1999) é difícil distinguir o que é público do que é privado no ambiente virtual, uma vez que nesse meio as relações se misturam e são compartilhadas de maneira muito mais ampla.

De acordo com Lévy (1996; 1999), o termo virtual é comumente utilizado com o objetivo de representar uma ausência de existência. Contudo, o virtual é algo que existe em potência, não em ato, ou seja, ele existe sem estar presente. $O$ virtual busca se atualizar, sem ter que passar pela materialização efetiva ou formal, isto é, ele pode ser encontrado antes de sua concretização. Portanto, o virtual se opõe ao atual e não ao real e, eles são apenas duas formas distintas de realidade.

Diante deste quadro, de uma sociedade que vive imersa em duas realidades, o real e o virtual, decidiu-se investigar como as pessoas têm percebido sua relação com o ambiente virtual e as consequências disso para sua vida. Buscou-se nessa pesquisa uma compreensão que disparasse reflexões sobre a influência do ambiente virtual na vida cotidiana, em busca de 
ampliar as discussões sobre um tema atual e relevante.

\section{MÉTODO}

Participantes

Participaram da pesquisa 40 estudantes universitários, maiores de 18 anos. O número de entrevistados foi definido em conformidade com o desenho metodológico e o objetivo da pesquisa. $\mathrm{O}$ número de entrevistados representa $1 \%$ dos estudantes dos cinco cursos de graduação da universidade onde foi realizada a pesquisa, sendo que foram entrevistados 8 alunos de cada curso. O roteiro continha 12 questões abertas sobre ambiente virtual que se relacionavam a compreensão do uso feito pelos estudantes (frequência, tempo, tipos de sites visitados, motivos e etc.) e a como eles viam as possíveis influências dessa ação em suas vidas, ou seja, no cotidiano. Estabeleceu-se como critério de inclusão na amostra: ser estudante universitário e ter mais que dezoito anos. A opção pela idade de 18 anos se deu por considerar que a maioridade civil permite que os entrevistados sejam responsáveis por sua livre participação na pesquisa. $O$ contato com os participantes foi feito por indicação e os entrevistados foram nomeados com nomes fictícios, escolhidos por eles após a entrevista.

Instrumentos

Trata-se de uma pesquisa qualitativa, exploratório-descritiva, que tem a Psicologia Ambiental como referencial teórico. $\mathrm{O}$ instrumento de coleta de dados foi a entrevista semiestruturada. Foi elaborado um roteiro prévio com questões sobre o uso dos ambientes virtuais, os sentidos atribuídos ao uso e como esse influencia a vida cotidiana das pessoas. O contato com os entrevistados se deu a partir de algum mediador conhecido destes. A pesquisa foi aprovada pelo Comitê de Ética em Pesquisa protocolo CAAE 12559319.8.0000.5401, sendo apresentado aos participantes o Termo de Consentimento Livre e Esclarecido, antes de cada entrevista. Elas foram gravadas e posteriormente transcritas integralmente.

\section{Análise dos Dados}

A partir da transcrição das entrevistas, realizou-se a análise que buscou atrelar os dados colhidos com o material científico disponível. Organizou-se a análise das entrevistas buscando discernir elementos na fala dos entrevistados que pudessem articular-se ao referencial teórico, de maneira a apresentar material que venha a contribuir para as questões deste estudo.

Desta forma, com o fim da coleta de dados, iniciou-se a análise das respostas obtidas para aprofundar o entendimento sobre a compreensão das pessoas entrevistadas, buscando aspectos da realidade que não podem ser quantificados (GERHARDT; SILVEIRA, 2009, p. 32). Assim, enfatizando a inferência da análise de dados, tentou-se suplementá-la utilizando citações sistemáticas das falas dos entrevistados, a fim de melhorar a exposição da análise e a efetiva compreensão do objeto proposto.

De acordo com Castro (2004), a análise foi conduzida por meio das seguintes etapas:

1) Escuta atenta, primeiro individualmente e depois em grupo nas supervisões -, dos dados colhidos nas entrevistas visando captar seu sentido e discutir suas implicações.

2) Novas escutas destacando e escrevendo as categorias de análise e os pontos de interesse, citados nos objetivos.

3) Comparação entre os relatos dos sujeitos, a fim de verificar os elementos comuns à maioria deles.

4) Descrição dos elementos que aparecem nos relatos dos sujeitos.

5) Compreensão dos dados, considerando o referencial teórico adotado no presente estudo.

Seguindo as etapas acima, espera-se ter conseguido fugir do subjetivismo e alcançado certo rigor científico. Nesse sentido, o estudo se baseou nas propostas de Bardin (2009) sobre a análise de conteúdo, que oscilam entre dois polos: o rigor científico e a riqueza da subjetividade. Dessa forma, foram organizadas quatro categorias de análise dos conteúdos elucidados nas entrevistas, foram elas: A compreensão de Ambiente Virtual; Tempo e Modo de Uso dos Ambientes Virtuais ; Influências dos ambientes virtuais nas Relações Sociais; e Possíveis consequências psicológicas do uso dos ambientes virtuais, que serão apresentadas a seguir.

\section{RESULTADOS E DISCUSSÃO}

A compreensão sobre o Ambiente Virtual

Nesta parte buscou-se a compreensão das pessoas sobre o ambiente virtual: como elas conseguiam descrevê-lo e explicá-lo. Com a 
realização das entrevistas, notou-se certa dificuldade dos entrevistados na descrição e elaboração das respostas. Contudo, o momento onde pediu-se uma definição própria do que é o ambiente virtual foi, sem dúvida, quando os sujeitos tiveram mais dificuldades para responder: a maioria deles, durante a resposta, relatou ser muito difícil falar sobre isso. Desta forma, pareciam responder de maneira sucinta para se livrar da questão. Tentando exemplificar - que foi dito acima, as respostas abaixo representam a integra do que foi falado pelos entrevistados, no momento em que respondiam à questão supracitada:

Acho que ambiente virtual é todo e qualquer espaço de relação, de conhecimento, de construção, que se dá no virtual, então é internet, a televisão, o celular, as redes sociais, o youtube, sei lá, todos os espaços, acho que é isso. (Cristina)

Cristina deixa claro que hesita diante da necessidade elaborar uma definição para o que é ambiente virtual, bem como mistura inúmeros elementos de sua vida cotidiana, como dispositivos eletrônicos e aplicativos para tentar atingir algum sentido possível para organizar sua resposta. Obviamente não se trata de uma tarefa fácil e não era esperado encontrar experts no assunto, mas sim, poder atingir algum entendimento sobre as formas pelas quais as pessoas compreendiam o tema, gerando, nesse momento, uma possível reflexão. Apesar da dificuldade encontrada para a elaboração das respostas, pode-se notar que, assim como a definição de ambiente, da Psicologia Ambiental (CAVALCANTE; ELALI, 2011), traz no seu bojo a noção de inter-relação, a entrevistada destaca esta característica relacional do ambiente virtual envolvendo pessoas, elementos físicos, culturais e funcionais do ambiente (off-line). Essa complexidade relacional talvez seja o motivo da dificuldade e do embaraço, pois sem dúvida complexifica qualquer análise e tentativa de síntese.

Outros entrevistados tiveram ainda mais dificuldades para a elaboração e responderam de forma quase que incompreensível. A resposta de Julieta é um exemplo disso:
Eu acho que é muito vasto, acho que vai da pessoa procurar o que interessa. Pra mim é uma coisa muito vasta, depende se você vai procurar uma coisa interna, ou uma coisa informativa é muito vasto. (Julieta)

Ao analisar-se as respostas dos entrevistados pode-se perceber que mesmo apresentando uma dificuldade para elaborar uma explicação sobre o ambiente virtual, esses diziam sobre a importância do tema, o que se apresentou também evidente na amplitude que estes relacionavam ao ambiente virtual. Compreendeu-se então que a dificuldade ligada à amplitude e à complexidade levavam a respostas ligadas à perplexidade e à incompreensão.

\section{É uma coisa muito grande eu não sei dizer. (Demétria)}

Nesse sentido, considera-se que o ambiente virtual no olhar dos entrevistados é algo da ordem do inexplicável, do incompreensível, mas que ao mesmo tempo é importante e permeia o cotidiano das pessoas, não sendo possível explicar e nem mensurar a extensão dele e a sua influência. Assim, chega-se à reflexão de que a incompreensão ligada ao que seria um ambiente virtual chama a atenção para o fato de que os entrevistados, jovens universitários, em sua maioria, nasceram em um contexto social onde o uso da internet e de ambientes virtuais já era uma realidade de certa forma consolidada, como um instrumento com diversos usos e finalidades, mas, mesmo assim, eles dificilmente refletem sobre seu significado ordinário, apesar da importância que possam the atribuir. Esta impossibilidade de entender um ambiente (o virtual) que vem se tornando onipresente na sociedade apresenta a necessidade de se debruçar sobre os estudos acerca da virtualidade e do uso dos ambientes virtuais, pois se ele for indiscriminado, como algo que não passa pela reflexão dos jovens, que apresenta-se como algo automático e natural, poderia levar a usos extremamente nocivos. Hodiernamente é muito comum a ligação de crimes, como suicídios e pedofilia, estarem vinculados ao uso do ambiente virtual. Se não for 
possível compreender tal ambiente, em toda a sua complexidade, a sociedade corre o risco de se tornar seu refém, deixando assim, de utilizar suas potencialidades criativas, se afundando em destruição e quem sabe até mesmo invocando neoludismos.

\section{Tempo e Modos de Uso dos Ambientes}

\section{Virtuais}

Se, por um lado foi difícil para os entrevistados definir o que é o ambiente virtual, por outro, falar sobre ele e seus usos se apresentou como uma tarefa mais imediata. Um ponto extremamente importante para se destacar nas respostas é a frequência do uso dos dispositivos eletrônicos conectados à internet (celulares, computadores, tablets e etc.): em uma das entrevistas, quando perguntado "quanto tempo, por dia, você utiliza seus equipamentos eletrônicos?" o entrevistado responde sem sobressaltos, ou comentários:

\section{"Praticamente o dia inteiro, só no período de aula que às vezes não dá." (Marcos)}

A resposta "o dia inteiro" foi a mais frequente para essa pergunta, principalmente quando se remetia ao uso do telefone celular. Este dispositivo acumulou muitas funções desde sua criação, quando seu principal recurso era a comunicação móvel por voz entre as pessoas em longa distância. Hoje em dia, dentro dos diversos modelos já existentes, os chamados smartphones, que se modernizam e atualizam todo ano, é possível além de estabelecer uma comunicação com envio de áudios, imagens, vídeos, documentos e etc., também ter acesso a diversos aplicativos prontos para garantir a satisfação de qualquer necessidade de maneira rápida, prática, onde o usuário estiver, no momento que ele quiser, contando que haja acesso à internet. A ANATEL (Agência Nacional de Telecomunicações) divulgou que atualmente já são 273,58 milhões de aparelhos e densidade de 1,3 linhas por habitante. Sobre isso Coutinho (2014, p. 10) afirma:

o que mais impressiona não é a quantidade, mas o avanço tecnológico por que passaram estes aparelhos, que hoje funcionam como verdadeiros computadores de bolso com capacidade de processamento semelhante ou superior aos computadores do começo da década, com funções e aplicações em praticamente todas as áreas do conhecimento humano.

E isso fez com que houvesse um crescimento na procura destes aparelhos, seja por crianças, seja entre adultos ou idosos, os celulares têm conquistado um enorme mercado consumidor, se tornando um dos itens mais desejados e usados da sociedade atual. Sobre o tempo de uso diário de aparelhos eletrônicos, a participante relata:

Engraçado que eu tenho um aplicativo para medir o tanto de tempo que eu fico no celular, ele se chama Moment, ele conta quanto tempo você fica olhando no celular é bem interessante e, eu fico tentando ter um controle disso, porque acho horrivel quando a gente mexe muito no celular $e$, segundo o aplicativo eu fico... normalmente... em média umas três ou quatro horas por dia no celular olhando pra ele. Só que não só em redes sociais, porque eu assisto coisas no celular, tipo série essas coisas, então isso conta, não é só Facebook essas coisas; pesquisas da faculdade também faço no celular, então é, em média, umas três a quatro horas por dia. (Cristina)

Essa resposta remete a uma necessidade de algo (que no caso acaba sendo um aplicativo pertencente ao próprio celular) que monitore o uso desse aparelho, para que assim haja o conhecimento do tempo de uso e, então, gere uma tentativa de controle sobre o mesmo. Tal fato poderia levar a suposições sobre possíveis incômodos, dos entrevistados, diante de certa consciência de um uso exagerado, ou seja, diante de uma possível obrigação atual de manter-se conectado, a todo momento. Contudo, vale ressaltar que Cristina foi a única entrevistada que 
relatou sentir algum incômodo com seu tempo de conexão à internet e aos ambientes virtuais.

Considerando que a resposta mais frequente sobre o tempo de uso foi o dia inteiro e que apenas uma entrevistada colocou sentir um incômodo tentando controlar o seu uso dos ambientes virtuais, evidencia-se que entre os jovens universitários existe uma conexão direta e permanente aos ambientes virtuais e que estes são parte fundamental de seu cotidiano, uma vez que realizam ampla gama de atividades neste contexto. Considerando-se esta questão, então algumas reflexões se apresentam como necessárias: como pensar as relações humanas na atualidade atravessadas pelos ambientes virtuais? Quais os benefícios e prejuízos dessa conexão produzida pela via da virtualidade? A fala dos entrevistados apresenta o uso dos ambientes virtuais como algo natural em suas vidas e estes apontam sentir necessidade de se manterem conectados constantemente, evidenciando o quanto os ambientes virtuais têm sido investidos do tempo dos jovens, sendo um facilitador na realização de algumas atividades, mas também algo que pode produzir um distanciamento nas relações, o que poderia levar ao aumento do individualismo, tema tão discutido atualmente.

Considerando que os entrevistados utilizam os ambientes virtuais a maior parte do dia, buscou-se saber onde estes investem seu tempo. As respostas trouxeram que o maior e mais notável uso do ambiente virtual é para redes sociais, principalmente através dos celulares, como se vê nesse exemplo em que as pessoas são questionadas sobre "o que você mais gosta de fazer nesses ambientes virtuais" e a resposta é:

Acho que ficar nas redes sociais, é, eu faço outras coisas, mas não tanto tempo quanto eu passo nas redes sociais. (Aparecida)

Eu assisto série e estudo no computador $e$, no celular, é mais redes sociais (Gabriela)

Computador eu uso mais pra assistir series e pra estudar e o celular mais pra redes sociais (Regina) Celular é rede social e computador é mais pra estudo e ouvir música $e$ redes sociais também, mas eu uso mais no celular (Antônio)

Para Rosa, Santos e Faleiros (2016), um dos fatores que contribuiu muito para o grande interesse das pessoas pelas redes sociais, ou ambientes virtuais de relacionamentos foi a criação e o uso dos "avatares" (uma representação sobre o usuário e que permite as interações onde a identidade pode permanecer não revelada), pelos perfis. Ainda segundo os autores supracitados, a cotidianidade das interações facilitadas pelas tecnologias de informação e comunicação, particularmente por meio das redes sociais, através dos celulares, faz com que milhões de pessoas passem parte considerável do seu dia em ambientes usualmente denominados "virtuais". As redes sociais permitem às pessoas serem como desejarem, mostrarem suas vidas da forma que quiserem, e se comunicarem intensamente, a qualquer hora, de maneira rápida e quase que totalmente independente do lugar onde estão. É possível acessar parte da vida de pessoas do mundo todo, além de comunidades e páginas, com assuntos interessantes, servindo tanto para o entretenimento, quanto para o acesso a informações. No entanto, os resultados desse uso é que nem sempre são benéficos, seja pelo tempo dispensado a isso e subtraído de outras atividades cotidianas, seja por diversos problemas de conteúdo das interações.

Assim, considerando que a maior parte do tempo investido pelos jovens universitários entrevistados é em redes sociais e que estas são o maior interesse destes nos ambientes virtuais e articulando com o que Rosa, Santos e Faleiros (2016) apontam, pode-se dizer que as conversas, os encontros, a ligação com as outras pessoas na atualidade é completamente atravessada, no cenário atual, pelos ambientes virtuais, sendo que estes são maciçamente investidos como uma forma de diversão, entretenimento, onde se vivem amores, amizades e etc. Porém como as autoras citadas apresentam, as redes sociais permitem que se crie uma "ilusão" de quem se é, de como se é, uma personagem de si mesmo, onde o que é mais importante é mostrar-se para o outro e assim se ligar a ele. Nesse sentido, surgem questionamentos: o que estes jovens buscam a partir da construção desses personagens? Como lidam consigo mesmos? O que os faz priorizar a ilusão sobre si e sobre o 
outro nas suas formas de se relacionar? Estas questões apontam para a necessidade de se refletir sobre esta busca, que não foi o objetivo deste estudo neste momento, mas que apresenta-se como uma pergunta importante a ser discutida e problematizada.

Porém, nessa pesquisa, buscou-se entender também como que os jovens veem a influência dos ambientes virtuais em suas relações sociais, que será apresentado a seguir.

\section{As influências dos ambientes virtuais nas}

\section{Relações Sociais}

Tendo em vista o que foi exposto acima, é possível pensar sobre o quanto se tornou essencial o uso de ambientes virtuais, principalmente por meio dos celulares, para a vida cotidiana. Visto que dentro de todas as instâncias do dia a dia - estudo, trabalho, relacionamento, família, amigos - é muito difícil, nos tempos atuais, não se utilizar nenhuma via dentro da internet para exercer algumas destas relações sociais. Retomando a compreensão de ambiente proposta por Moser (2018) e exposta em nossa introdução, vê-se o ambiente virtual atravessando os diversos tipos de ambientes propostos pelo autor, apresentando assim, uma influência pulverizada e intensa em vários níveis da vida cotidiana. Para ilustrar o que foi dito acima pode-se destacar a resposta de Cristina quando perguntada se "o uso dos ambientes virtuais influenciam suas relações sociais?":

Sim, acho que sim, pra eu conversar com quem não tá perto, o dia inteiro eu fico no celular, pra conhecer pessoas novas também, normalmente é sempre através do celular ou do computador, então acho que influencia totalmente. (Cristina)

Levando em consideração a influência dos fatores psicossociais do ambiente para a existência humana, principalmente as destacadas pela Psicologia Ambiental (CAMPOS DE CARVALHO; CAVALCANTE; NÓBREGA, 2011), pode-se imaginar que os modos de subjetivação sofreram diversas alterações no mundo com a existência da tecnologia e com todos esses aparelhos eletrônicos móveis. Cada vez mais as pessoas se transformam em seres com urgência e pressa, que necessitam de respostas rápidas, a todo instante. Sendo assim, fica ainda mais difícil abrir mão de um smartphone pequeno, pois é possível carregá-lo para qualquer ambiente o que dá a possibilidade de acessar qualquer site ou aplicativo, fazer compras, acessar agendas, ver a previsão do tempo, ou até mesmo, se comunicar com qualquer pessoa em qualquer lugar do mundo, instantaneamente, através das redes sociais. Contudo, essas facilidades atuais têm diminuído a frequência a alguns ambientes offlines, como quando se assiste um filme pelo computador e deixa-se de ir ao cinema, quando as compras são feitas pelo celular e deixa-se de ir à loja, entre outros. Além disso, salta aos olhos como o comportamento humano tem se alterado em ambientes como restaurantes, salas de aula, trabalho e etc.

A fala abaixo exemplifica o que foi dito acima especificamente no que se refere a interferência do ambiente virtual na sociabilidade das pessoas, pois quando perguntado se os ambientes virtuais influenciam nas relações sociais ela responde:

Influenciam, muitas relações
começam nas redes sociais,
muitas relações continuam
nas redes sociais, como você
se porta também... Ah não
sei, como você é numa rede
social, no ambiente virtual é
diferente de como você é na
realidade... Porque as coisas
são mais fáceis, você pode
ser qualquer pessoa numa
rede social, porque você tá
livre de julgamentos rápidos
assim. (Aparecida)

A fala de Aparecida, bem como a de outros entrevistados, traz a questão já anteriormente debatida de que o ambiente virtual produz a possibilidade de você construir uma personagem sobre si mesmo e que esta tem sido um conforto para aqueles que fazem uso desses ambientes como forma de relacionamento, levando muitas vezes à um afastamento da realidade, uma vez que o ambiente virtual apresenta-se como um espaço mais fácil de se relacionar e de se proteger do julgamento do outro, além de trazer velocidade e imediatismo para as relações. Talvez essa invisibilidade no ambiente virtual esteja contribuindo para uma remodelação da sociabilidade, já que parece haver certa ausência do outro, e consequentemente da forma como ele recebe o conteúdo que é comunicado. 
Levy (1996; 1999) coloca que é importante considerar o virtual, não como uma oposição a realidade, mas como uma nova realidade híbrida para a existência humana, e que talvez seja um caminho mais efetivo para compreender os impactos do ambiente virtual na vida cotidiana, considerá-lo desta forma. Assim se torna relevante verificar a importância das características desse ambiente e suas consequências nos relacionamentos sociais.

Os entrevistados responderam que as relações no ambiente virtual influenciam mais a vida pessoal no "ambiente real" do que viceversa, como aparece na resposta abaixo:

\section{Elas são complementares, mas eu acho que não se influenciam mutuamente, acho que a rede social acaba influenciando mais a realidade do que a realidade influencia a rede social, pelo mesmo motivo da outra pergunta, porque nas redes sociais a gente pode ser a pessoa que a gente quer e não quem a gente realmente é.(Aparecida)}

Portanto, foi relatado que o que se faz no ambiente virtual, quem se conhece nesse ambiente, causa mais mudanças na sua vida como um todo (na sua vida social principalmente) do que as pessoas conhecidas e as situações vividas fora desse ambiente. Acerca disso, Deleuze (1996) diz que o mundo virtual não se opõe ao real, mas o permeia, sendo uma condição de possibilidade para o atual. Com isso, as relações interpessoais off-line também acabam sendo mediadas, ou até mesmo influenciadas pelos dispositivos eletrônicos.

Influencia, porque assim teve muita gente que eu conheci pela internet e isso acabou me influenciando sabe, tipo tem pessoas que por conta deu ter conhecido pela internet eu tenho mais contato com essas pessoas do que com as que eu conheço pessoalmente, por isso acho que isso influencia bastante, porque tem muita gente que eu tenho muita amizade e que eu nunca

vi

pessoalmente.(Antonio)

Considerando a fala dos entrevistados, pode-se dizer que os ambientes virtuais têm se configurado como mediadores do estabelecimento e da manutenção de relações amorosas e de amizade na sociedade atual. Essas relações, apesar de terem configurações diferentes das iniciadas e mantidas pessoalmente, visto que as pessoas se comunicam, apenas, através de uma tela, muitas vezes sem ter nenhum contato físico, parecem, devido à fala dos entrevistados, requerer certo investimento afetivo, atingindo as emoções, atitudes e pensamentos, transformando os modos de vida que se constituem na sociedade como um todo. Evidencia-se então que o uso dos ambientes virtuais tem apresentado novas formas de sociabilidade que se organizam no cenário atual. Estas novas formas de sociabilidade certamente trazem consequências para os modos de subjetivação, sendo de extrema importância refletir sobre essas novas roupagens para os modos pelos quais as pessoas se relacionam na contemporaneidade.

Possiveis consequências psicológicas do uso dos ambientes virtuais

Ao indagar se os entrevistados acreditam que $o$ ambiente virtual afeta as pessoas psicologicamente, eles responderam que sim.

Acho que sim, acho que principalmente as redes sociais, porque, eu acho que eu nem tanto, por eu não utilizar muito, mas, quem utiliza muito as redes sociais, eu acho que psicologicamente é um grande problema, por causa dessa sociedade virtual de consumismo, individualismo, baseada na aparência e curtidas. Então, quem realmente está inserido nesse contexto de redes sociais $e$ sei lá, viciado nisso, está sempre preocupado com o que vai postar, com o que vai mostrar para os outros, se vai curtir ou se não vai $e$, tudo isso influencia o psicológico das pessoas nesse sentido. (Joana) 
Na fala acima, a entrevistada menciona que as redes sociais são baseadas na aparência e na quantidade de curtidas, havendo um consumismo e um individualismo, que pode gerar nas pessoas um sofrimento quando tentam se encaixar nos padrões exigidos pelas redes sociais. Esses padrões, construídos na virtualidade, apresentam-se cada vez mais exigentes, pois se mostram ligados à uma ilusão de perfeição, seja a partir da publicação sobre seus corpos, dos passeios e viagens, das atividades acadêmicas e laborais. O que se percebe então, é que a maioria das postagens na rede são construídas a partir da ideia de mostrar ao outro a vida vestida de perfeição, o que faz, muitas vezes, que os jovens se vinculem à essas imagens ilusórias como algo que devem almejar. Diante disso, passam a buscar como algo real uma idealização da vida cotidiana, inexistente para a grande maioria das pessoas, o que leva a experiências de sofrimento, aumentando os níveis de auto exigência e de ansiedade. Outros entrevistados também apresentaram respostas com este conteúdo:

Sim, a vida perfeita, acho que influencia, porque vai tá todo mundo achando que a vida tem que ser perfeita, sendo que a vida não é e, acho que a ansiedade também, porque acho que as coisas nos ambientes virtuais são muito rápidas e a gente acaba perdendo a paciência pra lidar com as coisas na vida real (Bruna)

Geralmente a autoestima fica bem "sequeladinha". Na verdade tem todo uma coisa de ostentação dentro da internet, então quando você não tá nesse perfil você fica meio mal. Minha autoestima às vezes fica meio baixa por causa da internet. (André)

Nessas respostas, tanto a Bruna quanto o André acreditam que, as redes sociais podem causar um sofrimento psíquico. Para Felden et al. (2015, p. 3332-3333) imagem corporal pode estar atrelada à facilidade de acesso aos meios midiáticos, principalmente aqueles relacionados às redes sociais, sendo a internet representada como um potente meio sociocultural que contribui para a distorção da imagem corporal, ao qual os adolescentes estão frequentemente expostos, tornando-se um grupo de risco.

De acordo com os autores acima, as redes sociais podem afetar a forma como as pessoas veem os seus corpos, podendo gerar um sofrimento psíquico, bulimia e anorexia, que causam distorções da imagem corporal, por exemplo, entre outros problemas ligados a como os jovens tem se vinculado aos ambientes virtuais e $o$ que estes buscam nessas experiências, nesse tipo de ambiente.

$\mathrm{Na}$ resposta de Bruna, que foi mencionada acima, ela também cita sobre a questão da efemeridade nas redes sociais. Vivese em um tempo em que é necessário ser veloz, o que segundo Trivinho (2007), se apresenta como uma característica da contemporaneidade e que traz consequências para a vida das pessoas, como a ilusão de que tudo é rápido, que não existe espera. A forma veloz em que se dão os acontecimentos nos ambientes virtuais fazem com que os jovens apresentem sofrimento em situações cotidianas comuns, como esperar por algo, ou buscar algo a partir de um processo de construção. Diante do imperativo da velocidade, a espera, o processo e a construção são aspectos sociais que devem ser anulados, pois se configuram em fatores que geram sofrimento em uma sociedade, sob as influência do ambiente virtual, onde a frustração deve ser diminuída, ou mesmo eliminada.

Um outro aspecto que apareceu na fala dos entrevistados foi a dificuldade nos relacionamentos em ambientes virtuais e a vivência de experiências de Cyberbullying, que é um tipo de violência praticada contra alguém através de meios eletrônicos de comunicação e interação. No entanto, o tema é tratado de forma diferente pelos entrevistados, principalmente no que se refere aos seus efeitos, pois na fala de Gabriela aparece destacado o sofrimento e na de 
Marcos, além dele, uma possibilidade de aprendizagem social, como um treino virtual de sociabilidade.

Sim, com certeza, ah eu acho que, por exemplo, o bullying que as pessoas sofrem virtualmente influencia elas psicologicamente.

(Gabriela)

Sim, principalmente pela questão do cyberbullying, muitas vezes a pessoa que sofre acaba sendo influenciada negativamente, ou às vezes pode até fortalecer a pessoa, por exemplo, uma pessoa que acaba sofrendo o cyberbullying só que ela já tem uma mentalidade preparada para esse tipo de coisa, ela pode simplesmente se distanciando, que pode ser visto ruim, mas acaba distanciando de um público que quer lhe fazer mal, que acaba sendo bom, então pode servir como um meio de filtrar as amizades que você pode vir a ter.(Marcos)

De acordo com Wendt e Lisboa (2013) essa agressão virtual está aumentando rapidamente e, elas podem acontecer de diversas maneiras. Shariff (2011, p.78) coloca:

As formas mais comuns de cyberbullying ocorrem, geralmente, através do envio de e-mails, mensagens de texto, divulgação de fotos e vídeos ofensivos, manipulação de imagens, insultos em salas de batepapo ou em redes sociais, que podem ser anônimos e atingir um público infinito de expectadores em pouco tempo.

Os modos como se apresenta o cyberbullying são bastante distintos, assim como as pessoas que vivenciam essa experiência a encaram de formas distintas, sendo difícil se ter um controle sobre ele, mas o que fica evidente é que a violência vivida traz ressonâncias na vida dos sujeitos como apontam Wendt e Lisboa (2013, p.78-79) quando falam sobre os prejuízos desse tipo de violência:

[...] os jovens envolvidos nas formas de agressão online têm prejuízo no desenvolvimento e manutenção de algumas habilidades sociais (Kowalski \& Limber, 2007; Steffgen et al., no prelo). Em outras palavras, um dos riscos que o cyberbullying pode oferecer aos jovens é o déficit no desenvolvimento de sua capacidade empática.

Nesse sentido, pode-se considerar que essas experiências de violência vividas no virtual têm causado danos psicológicos, já que os jovens muitas vezes buscam a sociabilidade em ambientes virtuais pois acreditam que neles estão mais seguros e protegidos nas relações que estabelecem; contudo, quando acabam vivenciando essas experiências, eles têm que lidar novamente com as fragilidades $e$ as dificuldades de relacionamento com os outros, com as diferenças e com a frustração, características importantes dos modos de vida que se organizam na sociedade atual. Went e Lisboa (2013) colocam que diante de toda essa violência e da elucidação que a sociabilidade nos ambientes virtuais também apresenta dificuldades, há uma taxa crescente de tentativas de suicídio ligadas ao cyberbullying. Os autores mostram que pesquisas realizadas com adolescentes vítimas de cyberbullying indicam que estes podem estar mais propensos a tentar suicídio do que aqueles que não experimentam essas formas de agressão entre pares (CASSIDY, JACKSON e BROWN, 2009). Patchin e Hinduja (2010) constataram em suas pesquisas que os participantes envolvidos com 0 bullying ou cyberbullying, tanto os agentes como aqueles que são vítimas, apresentaram maiores frequências de ideação suicida e também mais propensos a tentar suicídio em comparação aos estudantes que não haviam sido expostos a essa violência.

Went e Lisboa (2013, p.82) relatam também que "cerca de $25 \%$ das vítimas de 
cyberbullying não buscam atendimento especializado" e, isso pode causar danos graves ou irreversíveis: suicídios, homicídios e massacres em lugares públicos. Além disso, afirmam que os sintomas de depressão e ansiedade podem ser desenvolvidos em adolescentes vítimas de cyberbullying.

Assim, o que pode-se considerar, ao se refletir sobre as consequências psicológicas dos ambientes virtuais na vida dos jovens universitários, é que embora a sua busca seja apresentada por eles como algo natural, algo inerente à vida na atualidade, o uso desses ambientes se dá pela busca de respostas aos ideais contemporâneos ligados à uma vida espetacular (DEBORD, 1997), à satisfação dos próprios desejos acima de tudo (LASCH, 1983), à velocidade das relações e à busca da satisfação imediata, enxergando esses ambientes como facilitadores na busca por esses objetivos. Notouse também que os jovens buscam os ambientes virtuais porque acreditam que as relações são mais fáceis nele e que nele estão protegidos dos danos que o contato em ambientes reais poderia causar a sua pessoa e aos seus objetivos, à satisfação de seus desejos.

Porém, o que se percebe é que ao se depararem com os problemas presentes nos ambientes virtuais, como o cyberbullying, os usuários são novamente apresentados às suas fragilidades, pois sofrem por não conseguirem atingir os padrões apresentados pela virtualidade, ficam ansiosos por não terem respostas imediatas e se percebem inseridos em experiências de violência. Desta forma, no ambiente virtual estes jovens também vivenciam dificuldades que os as apontam para aquelas que são fundamentais nos modos de vida off-line: o relacionamento com o outro, a necessidade de renúncia, de frustração, de troca, a espera, o tempo e a violência das relações; e assim podem perceber que a ideia de proteção que vincularam ao ambiente virtual é mais uma das ilusões que este promove, uma ilusão buscada para se proteger da dor e do sofrimento, condições inerentes à existência, sendo algo que o sujeito terá que lidar, seja nos ambientes reais, seja nos virtuais. Porém, a vivência dessa desilusão de um ideal ligado ao virtual, traz danos significativos, pois fragiliza ainda mais o sujeito, forçando-o a buscar força e apoio para lidar com questões tão importantes da vida em sociedade.

Sendo assim, os ambientes virtuais influenciam a vida cotidiana, trazem impactos positivos e negativos para as relações, mas fica claro que estes, na fala dos jovens universitários, evidenciam e reproduzem dificuldades vividas no cenário contemporâneo, na conexão off-line entre as pessoas, na configuração das solidariedades fraternas e na tessitura vincular que sustenta a vida em comunidade. Cai-se novamente na necessidade de se compreender como parte integrante do ambiente, que é construído por ele, mas que também o constrói, devendo se responsabilizar e se implicar em suas ações. A busca por uma vida sem implicação, sem sofrimento vai se configurado em uma ilusão já que o ambiente virtual, apesar de complexificar a sociedade, trazendo novos aspectos e desafios, também reproduz a lógica das relações do real, afinal por traz das telas dos celulares e dos computadores, há um humano que as opera.

\section{CONSIDERAÇÕES FINAIS}

Ao fim dos esforços deste trabalho, fica claro que as pessoas conseguem reconhecer que o ambiente virtual, em suas mais diversas formas, têm impactos na vida cotidiana de seus usuários. No entanto, a extensão destes impactos nem sempre é tão bem compreendida, o que, talvez, possa se ligar a dificuldade de compreender a natureza deste ambiente: ampla e complexa. Pode-se verificar que os jovens universitários compreendem os ambientes virtuais como algo amplo mas inerente à vida contemporânea, trazendo impactos na forma como organizam sua vida, como controlam seu tempo, como se relacionam nesses ambientes e como gestam suas emoções.

Muitos entrevistados afirmaram que 0 uso dos ambientes virtuais é inerente ao seu cotidiano e ao modo como organizam suas vidas, trazendo consequências positivas ligadas às facilidades, à velocidade da comunicação, do conhecimento, mas apresentaram também desconfortos ligados às experiências de sofrimento, como a questão da autoestima, dos ideais ligados ao corpo, das relações amorosas e de amizade, e da efemeridade que sentem nessas relações. Os entrevistados apontaram também que se sentem protegidos no sentido de poderem ser quem quiserem nesses ambientes, mas que mesmo assim vivem experiências de violência, como o cyberbullying, que os deixa inseguros, ansiosos e "sequelados" (como dito por um dos entrevistados), o que evidencia pontos importantes a serem discutidos por novos estudos sobre ambientes virtuais. 
Talvez um limite deste estudo - que caracterizado como um estudo exploratóriodescritivo, apresentou questões diversas sobre os ambientes virtuais que foram discutidas a partir dos dados obtidos por meio das entrevistas realizadas - seja a necessidade de diversificação de instrumentos de coletas de dados e a necessidade de maior aprofundamento na busca da compreensão sobre os impactos da virtualidade na cultura e na vida cotidiana, para que possam se construir possibilidades criativas no uso dessas ferramentas.

Portanto, foi possível a partir deste estudo, enxergar e entender algo sobre a importância destes fenômenos no mundo hodierno e contribuir com a ampliação das discussões, vendo que essa pesquisa aponta para a importância de se inquietar e buscar, dentro do campo científico, aprofundar os conhecimentos existentes e as possibilidades de intervenção junto à sociedade, para desmistificar o ambiente virtual e suas consequências, expondo sua natureza e possibilidades, e fazendo com que seu uso se dê, cada vez mais, pelo viés dos benefícios que ele pode aportar à sociedade em geral.

\section{REFERÊNCIAS}

BARDIN, L. Análise de Conteúdo. Lisboa, Portugal: Edições 70, 2009.

CAMPOS DE CARVALHO, M. I.; CAVALCANTE, S.; NÓBREGA, L. M. A. Ambiente. In: CAVALCANTE, S. ELALI, G. A. Temas Básicos em Psicologia Ambiental. Petrópolis, RJ: Vozes, 2011.

CASSIDY, W., JACKSON, M., \& BROWN, K. N. Sticks and stones can break my bones, but how can pixels hurt me? Students' experiences with Cyber-Bullying. School Psychology International, Miami, Oxford, v.30, n.4, p.383-402, 2009. Disponível em: https://journals.sagepub.com/doi/10.1177/0143 034309106948. Acesso em: 04 out. 2017 https://doi.org/10.1177/0143034309106948

CASTRO, M. F. Asas do trabalho: um estudo do sofrimento no trabalho dos mototaxistas. 2004. 99 f. Dissertação (Mestrado em Psicologia do Trabalho) - Departamento de Psicologia Experimental e do Trabalho, Universidade do Estado de São Paulo, Assis, 2004.
CAVALCANTE, S.; ELALI, G. A. (orgs.) Psicologia ambiental: conceitos para a leitura da relação pessoa-ambiente. Petrópolis, RJ: Vozes, 2018.

COUTINHO, G. L. A era dos smartphones: um estudo exploratório sobre o uso dos smartphones no Brasil. 2014. 60 f., il. Monografia (Bacharelado em Comunicação Social) - Universidade de Brasília, Brasília, 2014. Disponível em: http://bdm.unb.br/bitstream/10483/9405/1/201 4_GustavoLeuzingerCoutinho.pdf. Acesso em: 10 abr. 2018.

DAQUINO, F. A história das redes sociais: como tudo começou. TECMUNDO, 2012. Disponível em: https://www.tecmundo.com.br/redessociais/33036-a-historia-das-redes-sociais-comotudo-comecou.htm. Acesso em: 09 out. 2017.

DEBORD, G. A Sociedade do Espetáculo, Tradução de Estela dos Santos Abreu. Rio de Janeiro: Editora Contraponto, 1997.

DELEUZE, G. O atual e o virtual. In: Alliez, E. Filosofia virtual . São Paulo, SP: Editora 34. P. 4758.

DORNELLES, J. Antropologia e Internet: quando o "campo" é a cidade e o computador é a "rede". Horiz. antropol., Porto Alegre, v. 10, n. 21, p. 241-271, Jun. 2004. Disponível em: http://www.scielo.br/scielo.php?script=sci_arttex t\&pid=S0104-

$71832004000100011 \& \operatorname{lng}=e n \& n r m=i s o$. Acesso em: 04 out. 2017 https://doi.org/10.1590/S0104$\underline{71832004000100011}$

FELDEN, Érico Pereira Gomes et al. Fatores sociodemográficos e imagem corporal em adolescentes do ensino médio. Ciênc. saúde coletiva, Rio de Janeiro, v. 20 , n. 11 , p. 3329 3337, Nov. 2015. Disponível em: http://www.scielo.br/scielo.php?script=sci_arttex $\mathrm{t} \& \mathrm{pid}=\mathrm{S} 1413$ -

$81232015001103329 \& \operatorname{lng}=e n \& n r m=i s o$. Acesso em 13 set. 2018 https://doi.org/10.1590/1413$\underline{812320152011.00212015}$

GERHARDT, T. E.; SILVEIRA, D. T. Métodos de pesquisa. Rio Grande do Sul: UFRGS, 2009. Disponível em: http://www.ufrgs.br/cursopgdr/downloadsSerie/ derad005.pdf Acesso em: 23 maio 2018. 
LASCH, C. A cultura do narcisismo. Rio de Janeiro: Imago, 1983.

LÉVY, P. Cibercultura. São Paulo: Ed. 34, 1999. Disponível em: https://mundonativodigital.files.wordpress.com/ 2016/03/cibercultura-pierre-levy.pdf. Acesso em: 28 out. 2017.

LÉVY, P. O que é o virtual?. São Paulo: Ed. 34, $1996 . \quad$ Disponível em: https://books.google.com.br/books?id=leNw_sO ADVEC\&pg=PA11\&hl=pt-

BR\&source $=$ gbs_toc_r\&cad $=4 \# v=$ onepage $\& q \& f=f$ alse. Acesso em: 30 out. 2017.

MOSER, G. Psicologia Ambiental. Estud. psicol. (Natal), Natal, v. 3, n. 1, p. 121-130, June 1998.

MOSER, G. Introdução à psicologia ambiental: pessoa e ambiente. Campinas, SP: Editora Alínea, 2018.

PATCHIN, J. W., HINDUJA, S. Cyberbullying and self-esteem. Journal of School Health, v.80, n.12, p.614-621, 2010. Disponível em: https://onlinelibrary.wiley.com/doi/full/10.1111/ j.1746-1561.2010.00548.x. Acesso em: 28 out. $2017 . \quad$ https://doi.org/10.1111/j.17461561.2010.00548.x

RIVLIN, L. G. Olhando o passado e o futuro: revendo os pressupostos sobre as inter-relações pessoa-ambiente. Estud. psicol. (Natal), Natal, v. 8, n. 2, p. 215-220, agosto de 2003. Disponível em http://www.scielo.br/scielo.php?script=sci_arttex t\&pid=S1413-

294X2003000200003\&lng=en\&nrm=iso. Acesso em: 16 abr. 2018. https://doi.org/10.1590/S1413294X2003000200003

ROSA, G. A. M.; SANTOS, B. R.; FALEIROS, V. de P. Opacidade das fronteiras entre real e virtual na perspectiva dos usuários do Facebook. Psicol. USP, São Paulo, v. 27, n. 2, p. 263272, Ago. 2016 . Disponível em: http://www.scielo.br/scielo.php?script=sci_arttex $\mathrm{t} \& \mathrm{pid}=\mathrm{S0103}$.

A65642016000200263\&lng=en\&nrm=iso >.

Acesso em: 16 abr. de 2018. https://doi.org/10.1590/0103-656420130026
SANTOS, M. O espaço dividido: os dois circuitos da economia urbana dos países desenvolvidos. São Paulo: EDUSP, 2004.

SANTOS, M. A urbanização brasileira. São Paulo: EDUSP, 2005.

SHARIFF, S. Ciberbullying: questões e soluções para a escola, a sala de aula e a família. Porto Alegre: ArtMed, 2011.

TASSARA, E. T. O.; RABINOVICH, E. P. Perspectivas da Psicologia Ambiental. Estud. psicol. (Natal), Natal, v. 8, n. 2, p. 339-340, Aug. 2003. Disponível em:

http://www.scielo.br/scielo.php?script=sci_arttex $\mathrm{t} \& \mathrm{pid}=\mathrm{S} 1413-$

$294 \times 2003000200018 \& \operatorname{lng}=p t \& t \operatorname{lng}=p t . \quad$ Acesso em: $\quad 28 \quad$ out. 2017. https://doi.org/10.1590/S1413$\underline{294 \times 2003000200018}$

TRIVINHO, E. A democracia cibercultural: lógica da vida humana na civilização mediática avançada. São Paulo: Paulus, 2007.

WENDT, G. W.; LISBOA, C. S. M. Agressão entre pares no espaço virtual: definições, impactos e desafios do cyberbullying. Psicol clin. Rio de Janeiro, v. 25, n. 1, p. 73-87, junho de 2013. Disponível em http://www.scielo.br/scielo.php?script=sci_arttex t\&pid=S0103-

$56652013000100005 \& \operatorname{lng}=e n \& n r m=i s o$. Acesso em 17 set. 2018. https://doi.org/10.1590/S0103$\underline{56652013000100005}$ 